\title{
Call for applications: Associate Editor, BDJ
}

The British Dental Association and Springer Nature invite applications for the post of Associate Editor, British Dental Journal.

The Associate Editor will be responsible for the commissioning, peer review process and publication of $B D J$ themed issues and series.

Key responsibilities include:

- Selecting themed issue and series topics

- Identifying and recruiting themed issue guest editors, where appropriate

- Commissioning articles

- Overseeing the peer review process for themed issues and series

- Scheduling publication of themed issues and series

- Ensuring themed issues are published according to schedule.

The successful candidate will be able to demonstrate:

- A significant academic reputation in dentistry and strong publication record

- An understanding of the aims and audience of the journal

- Fairness, objectivity, and integrity

- The administrative skills necessary to run the peer review process

- The ability to integrate the duties of Associate Editor alongside other commitments.
Editorial experience as an Associate Editor at other journals would be advantageous. Flexible role, c. 35 hrs per month.

About the Journal
The British Dental Journal (BDJ) is an international, peer reviewed
journal for the dental community, published by Springer Nature
on behalf of the British Dental Association. We aim to inform our
readers of ideas, opinions, developments and key issues in dentistry
- clinical, practical and scientific - to spark interest, debate and
discussion amongst dentists of all disciplines.
Application process
Applications should include:
- A full academic CV
- A statement explaining why the applicant wishes to become
Associate Editor and how the applicant would develop themed
issues and series
- Any other factors that would support the application.
An editorial stipend is available for this post.
The closing date for applications is 31 December 2020.
Please send applications by email, in PDF format, to Jonathan
Coe, Editor, BDJ (jonathan.coe@springernature.com).

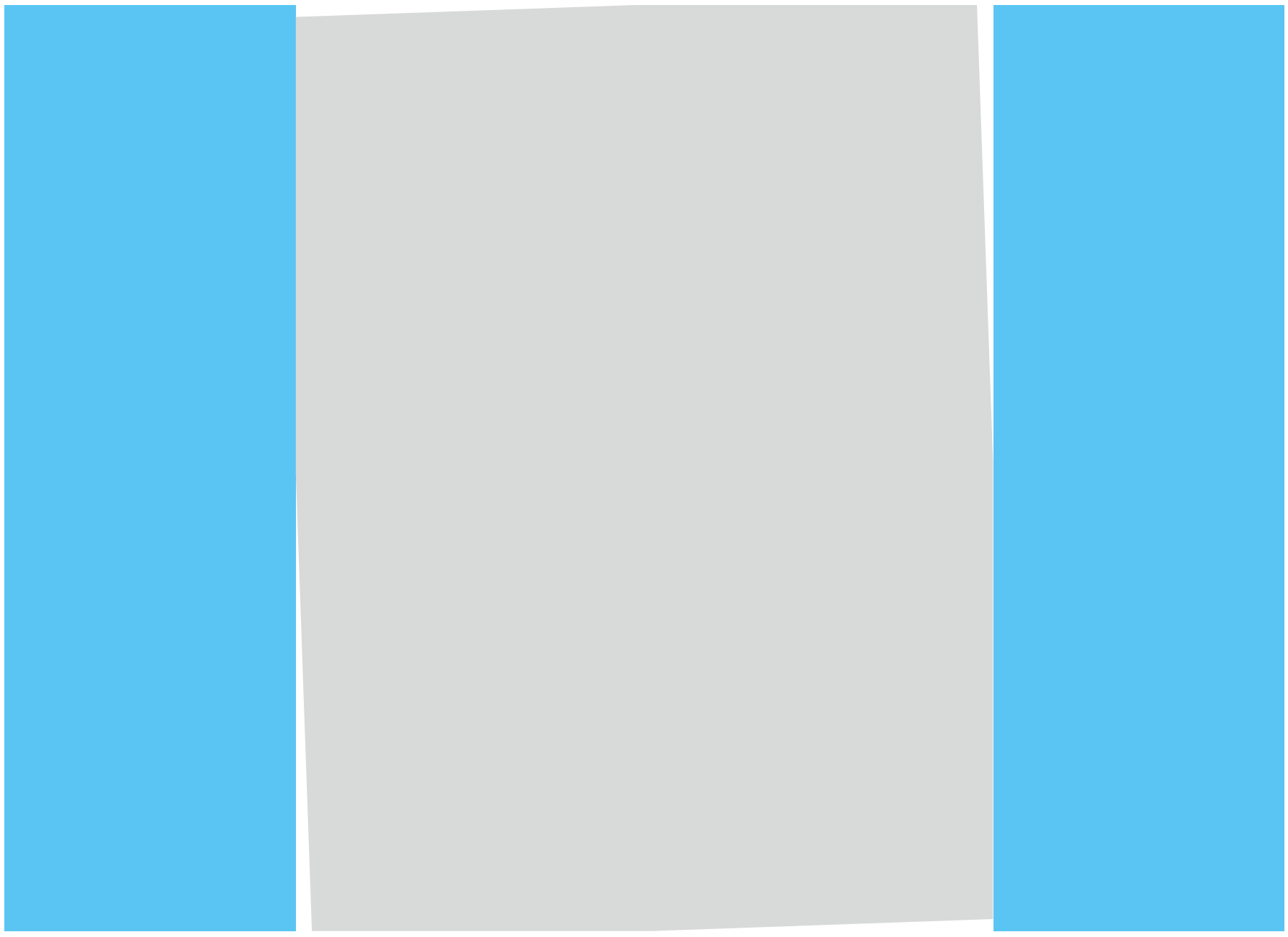

